\title{
TITLE:
}

\section{Learner participation patterns and strategy use in Second Life: an exploratory case study}

\author{
AUTHOR(S): \\ Peterson, Mark
}

\section{CITATION:}

Peterson, Mark. Learner participation patterns and strategy use in

Second Life: an exploratory case study. ReCALL 2010, 22(03): 273-292

ISSUE DATE:

2010-09

URL:

http://hdl.handle.net/2433/137212

RIGHT:

(C) Cambridge University Press 2010 


\title{
Learner participation patterns and strategy use in Second Life: an exploratory case study
}

\author{
MARK PETERSON \\ The Graduate School of Human and Environmental Studies, Kyoto University, \\ Yoshida-Nihonmatsu-Cho, Sakyo-Ku, Kyoto 606-8501, Japan \\ (email:M.Peterson@fx8.ecs.kyoto-u.ac.jp)
}

\begin{abstract}
This paper reports on an exploratory case study that investigates the synchronous interaction of intermediate level EFL learners in the 3D virtual world Second Life. The subjects took part in three seventy-minute chat sessions that involved the use of affordances provided by a purpose-built world within this environment. Analysis of the data revealed that the context and tasks appeared to elicit a high degree of participation. The interaction was highly learner-centered, with the majority of messages exchanged between students. The analysis further indicated that the subjects overcame initial difficulties to produce coherent target language output focused on the tasks through collaborative interaction involving the use of five transactional and two interactional discourse management strategies. Transactional strategies identified in the data were the use of split turns, time saving devices, addressivity, upper case and quotation marks. Interactional strategies were the use of politeness and keyboard symbols. The majority of these represented transfers from strategies used in non-computer-based forms of communication. The others were adaptive behaviours appropriate to the online medium. The consistent use of these strategies enabled the subjects to manage their interaction in an effective manner. Learner feedback was largely positive, and indicted that participation appeared to engender high levels of motivation and interest. This paper concludes by identifying areas of potential in future research on the use of 3D virtual worlds in CALL.
\end{abstract}

Keywords: Second Life, 3D virtual worlds, participation, strategies, interaction

\section{Introduction}

Contemporary research in SLA has increasingly focused on the role played by interaction in language development (Gass, 2000; Long, 1996). The literature indicates that language learning may be facilitated when learners are given access to communication contexts where beneficial types of collaborative interaction are fostered, through the use of carefully designed tasks based on learner needs (Pica, Kanagy \& Falodun, 1993). Influenced by this research, CALL researchers have explored, in a developing body of work, the use of computer-based communication environments such as chat rooms that enable learners to engage in novel forms of computer-based interaction. One type of computer-mediated communication (henceforth $\mathrm{CMC}$ ) environment that has attracted attention is the virtual world. 
These environments enable network-based real time communication involving the use of typed text and, more recently, audio between users within the context of a programmable 3D virtual world. The findings of learner-based studies have led researchers to identify a number of apparent advantages and issues associated with the use of CMC environments, including virtual worlds, in the context of networkbased CALL.

\subsection{Research on the use of synchronous CMC in CALL}

The current literature indicates that synchronous CMC environments may offer a number of advantages for language learning. As types of CMC that utilize typed text provide for anonymity, they may reduce anxiety and the influence of social context cues such as status that have been identified as hindering language development in traditional language classrooms (Hudson \& Bruckman, 2002). There is evidence in the literature that this aspect of interaction in CMC may enhance output, motivation and risk-taking (Chun, 1994; Kern, 1995; Warner, 2004). Moreover, the learner-centered nature of interaction in $\mathrm{CMC}$ and its suitability for innovative forms of task-based learning has been emphasized (Kötter, 2003; Smith, 2003). Studies have also drawn attention to additional benefits made possible by the computer-based nature of interaction in these environments. For example, types of CMC that involve the use of typed text support monitoring through the visual saliency of on-screen text, and the availability of scrolling (Swaffar, 1998). The data recording capacities of computers further provide educators with opportunities to use transcript data as an effective means to raise error awareness (Lee, 2001). Research on the use of real time text chat has drawn attention to the presence of strategies involved in the negotiation of meaning and other types of collaborative interaction identified in SLA research as playing an important role in language development (Blake, 2000; Darhower, 2002; Lee, 2002). Furthermore, studies conducted in international contexts have suggested that participation in CMC not only provides access to a wide range of interlocutors, it may also enhance crosscultural understanding and knowledge of the target language culture (Tudini, 2003; Von Der Emde, Schneider \& Kötter, 2001).

\subsection{Research on the use of $3 D$ virtual worlds in CALL}

Research on the use of 3D virtual worlds in CALL is limited, and many areas remain unexplored. However, current studies have produced largely positive findings and identify a number of potential advantages of interaction in these environments. These echo findings reported on the use of other types of real time CMC. For example, a high level of engagement has been reported in a number of studies (Deutschmann, Panichi \& Molka-Danielsen, 2009; Peterson, 2006). The capacity of virtual worlds to bring together diverse learner groups has been emphasized (Toyoda \& Harrison, 2002). Findings suggest that the specific communication features provided by virtual worlds may offer additional advantages for language learning. Researchers have observed that in virtual worlds the interaction takes place in virtual spaces that are user created (Svensson, 2003). As a result, feelings of immersion, community and emotional investment in the system are frequently enhanced (Ornberg, 2003). These 
beneficial aspects of interaction are reinforced by a unique feature of $3 \mathrm{D}$ virtual worlds: the presence of personal avatars. Researchers claim that the use of these virtual reality agents fosters new forms of identity exploration and the telepresence that is claimed to be necessary for effective communication in disembodied computer-based environments (Schroeder, 2002). Moreover, unlike in more conventional forms of CMC that utilize typed text, the avatars in virtual worlds are user controlled and can display in real time a range of non-verbal cues (such as gestures) and emotional states that play an important role in facilitating successful communication in non-CMC contexts. Current research, though not conclusive, nonetheless emphasizes the potential of virtual worlds as environments that may facilitate language development.

Research on the use of virtual worlds in CALL draws attention to a number of issues. These environments require that users have access to up-to-date computers and networks: conditions that are far from universal. In addition, the presence of network firewalls can be problematic. The literature shows that the potential of these environments is best maximized when users possess at least basic computer skills, and the need for learner training is further noted (Peterson, 2006). Finally, as with other types of $\mathrm{CMC}$, the potential exists for anti-social behaviors such as 'flaming'. Preventing abuse of the medium may require restrictions on user access and privileges. Although the current literature emphasizes that the use of virtual worlds is not without its challenges, taken as a whole, the literature suggests that these environments frequently present new opportunities to engage learners in beneficial forms of interaction. However, as researchers have noted, there is a pressing need for further studies that investigate learner behaviour in all types of CMC and in a wide range of contexts (Warschauer \& Kern, 2000; Conacher, 2004).

\section{Research rationale and questions}

The discussion in the previous section emphasizes the apparent potential of virtual worlds and draws attention to the need for additional learner-based studies. However, the literature has yet to conclusively establish the viability of virtual worlds as venues for effective task-based interaction involving small learner groups. The author is unaware of any research that has specifically focused on investigating the text-based interaction of intermediate EFL learners in Second Life. Moreover, little is known regarding learner participation patterns and strategy use in this type of virtual world. In order to fill this gap in the literature, this study will analyze the interaction of such a group and will answer the following research questions:

1. What are the significant participation patterns during learner task-based interaction in Second Life?

2. What strategies do learners use to manage their interaction?

3. What are learner attitudes toward studying in Second Life?

\section{Methodology and research framework}

In order to answer the research questions, this research adopts a case study that draws on qualitative methods with discourse analysis of learner transcripts as the 
main research instrument. This methodology was selected for the following reasons. This study is concerned with the investigation of a contemporary real life phenomenon within the framework of interactionist research. Moreover, it focuses on data collected from small groups under naturalistic conditions. An examination of the literature suggests that this type of data, when analyzed though the use of qualitative methods, can provide important new insights regarding the language development of individuals and small groups, while at the same time offering new perspectives on the opportunities afforded for language learning made possible by CMC technologies (Negretti, 1999). The literature further shows that learning in CMC is a complex phenomenon that requires the comprehensive approach provided by a case study (Waggoner, 1992). Another advantage of utilizing a case study was that it enabled a mix of qualitative research techniques to be incorporated into the overall research design. These included observation, field notes, pre- and post-study questionnaires and interviews. Adopting this mix of methods facilitated the collection of a wider and richer set of data sources than could be obtained through other means. Using a case study enabled the investigation to be conducted in-depth and over a sustained period, creating opportunities to collect more detailed data than may be obtained in more narrowly focused research techniques. Moreover, it also facilitated the identification of important patterns and themes in the data while also facilitating a micro and macro perspective.

\subsection{Subjects}

Seven intermediate level EFL students studying at a university in Japan participated in this research. Two of the subjects were undergraduates, the remainder were first year graduate students. All of the subjects were volunteers, and written consent was obtained regarding the collection and use of participant data. Responses to the prestudy questionnaire provided the following background information, which is summarized in Table 1. Each subject has been provided with a pseudonym (student 1). As Table 1 shows, the learners were Japanese and Chinese. The majority were Chinese and two of the subjects were male. The participants ranged in age from 22 to 40 years old and the median age was 25.8 years. Replies to the pre-study questionnaire further indicated that the participants possessed basic computer skills and that they had no previous experience of Second Life.

Table 1 Participant background information

\begin{tabular}{lllll}
\hline \hline & Nationality & Gender & Age & Language level \\
\hline \hline Student 1 & Chinese & female & 40 & intermediate \\
Student 2 & Chinese & female & 24 & intermediate \\
Student 3 & Chinese & female & 26 & intermediate \\
Student 4 & Japanese & male & 22 & intermediate \\
Student 5 & Chinese & female & 24 & intermediate \\
Student 6 & Japanese & female & 23 & intermediate \\
Student 7 & Japanese & male & 22 & intermediate \\
\hline \hline
\end{tabular}




\subsection{Procedures}

This research project ran over the latter half of the spring semester in 2009. After an initial orientation session, the group met once every two weeks over a six-week period running from early June until July. The subjects participated in three chat sessions held in the same location within Second Life. Each session lasted approximately seventy minutes. However, the length of each session varied somewhat due to occasional lateness. All of the sessions took place in a computer lab at the researcher's university. During each session, the subjects were located at separate computers within this lab. The researcher was present in-world during each session. At the beginning of each session, the researcher provided a handout and explanation of the task. The subjects were requested to work in pairs or groups if possible. However, because of occasional lateness and technical issues the groups were not necessarily the same for each of the three tasks that were undertaken.

\subsection{Tasks}

In order to explore the possible influence of task induced effects three tasks were administered. The selection of the tasks was influenced by the literature on taskbased learning. In creating the tasks the researcher drew on studies (e.g., Chapelle, 2001) which indicate that in synchronous CMC the most successful tasks are authentic in nature, meet learner needs, and provide opportunities to engage in active use of the target language (TL). The design was further influenced by research conducted in virtual worlds indicating that the most effective tasks are those that make use of the specific affordances provided by these environments (Hampel, 2006). The tasks were also designed to motivate learners, while at the same time eliciting types of strategy use associated with second language acquisition (SLA).

The first task was open-ended and involved learners in activities designed to facilitate participation and communication within the virtual world. Specific activities included in this task were: explaining features of the virtual world to peers; responding to questions; exploring and utilizing the communication features of the avatars. As the subjects were novice users of Second Life, this task was considered appropriate to the initial stage of the research. In the second task, the participants were requested to exchange opinions on a recent influenza outbreak in Japan. This task type was chosen as the literature suggests that opinion-exchange tasks focusing on contemporary issues of interest to learners may be a successful means to elicit the types of strategy use involved in language learning during learner interaction in virtual worlds (Peterson, 2006). The final task involved two stages. In the first stage, prior to the main session, the subjects were requested to read a number of articles on studying in virtual worlds. In the second stage, they were directed to locate a custombuilt lecture theater within Second Life where each subject delivered a short presentation and took questions. This task was implemented in order to meet specific learner needs by providing practice in important aspects of presentation, including skills such as interrupting, expressing disagreement and responding to critical questions appropriately. 


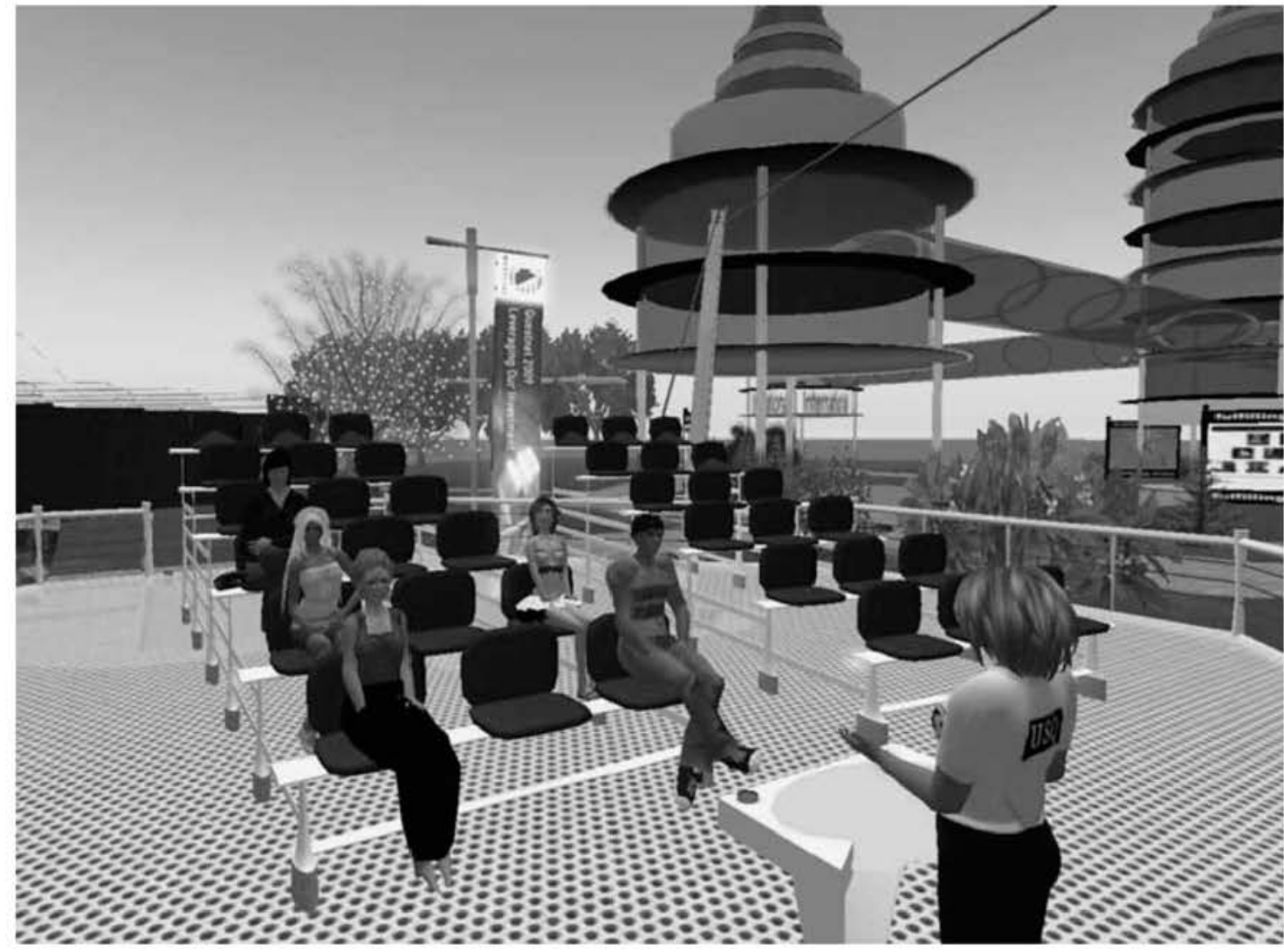

Fig. 1. The lecture theater in USQ Island

\subsection{The USQ Island virtual environment}

The interaction investigated in this research was conducted in a specially designed world within Second Life called USQ Island. This environment is hosted at the University of Southern Queensland in Australia ${ }^{1}$. This 3D virtual world is modeled on a university campus in Australia and contains a number of special features that are designed to facilitate learning. Among these is a purpose-built lecture theater. A screen capture of the subjects in this facility during the third task session on presentation may be seen in Figure 1.

Another innovative feature utilized in this research was the opinionator, a $3 \mathrm{D}$ Likert scale graphing tool. In the opinionator, learners can respond to questions by moving their avatars to different sections marked strongly agree, agree, neutral, disagree and strongly disagree. The total number of avatars in each section and the percentage for each answer is then automatically displayed in real time. A screen capture of this innovative affordance utilized during the opinion-exchange task, administered in the second task session, may be seen in Figure 2.

In addition to the above features, USQ Island provides access to social facilities that would be found on a typical university campus in Australia, including a student information centre, lounge and club. This virtual world was selected as the research

1 The researcher is grateful to Lindy McKeown, Ann Smith and the University of Southern Queensland for providing access to USQ Island. 


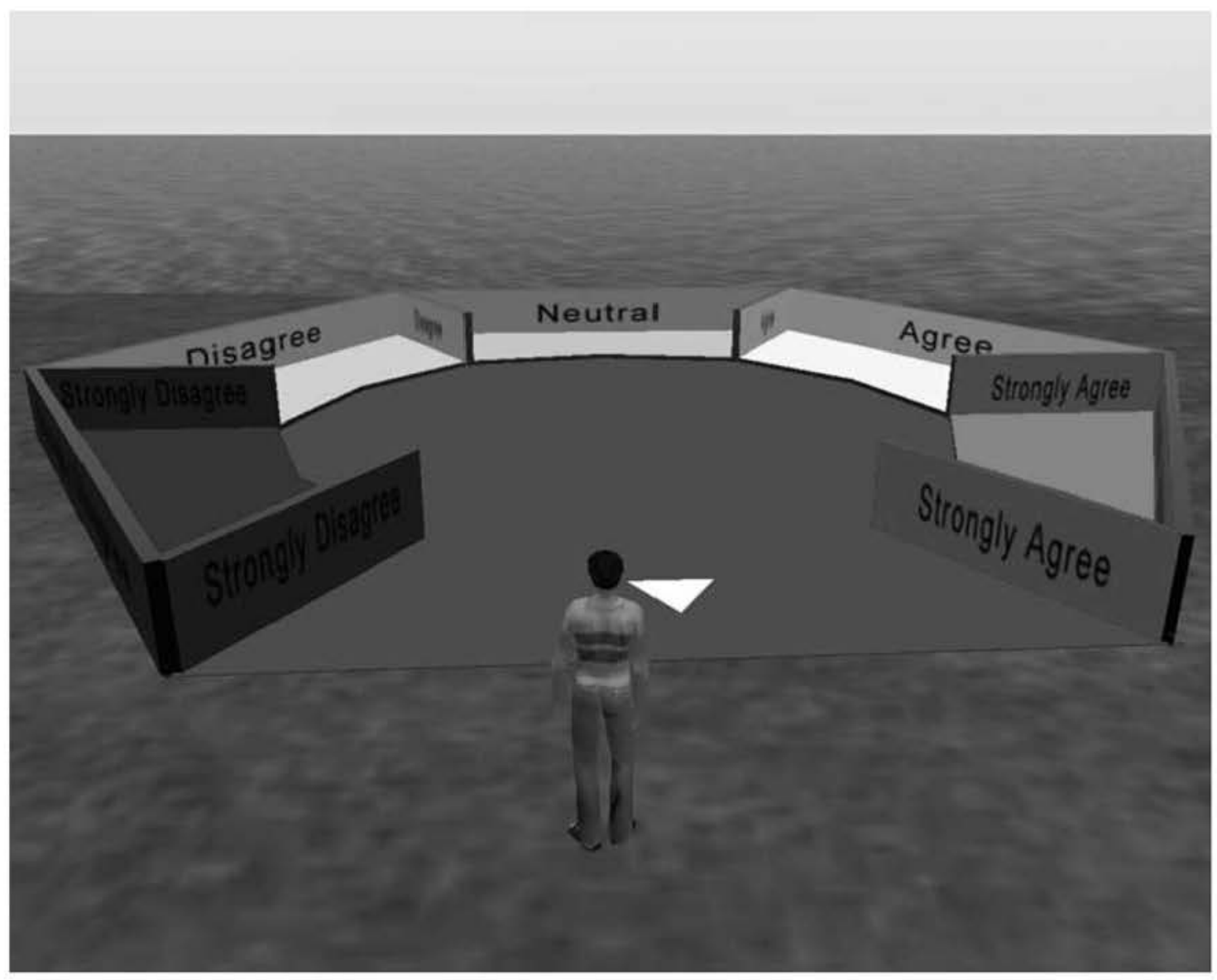

Fig. 2. The opinionator in USQ Island

venue, because USQ Island provides an accessible and robust platform that restricts access to authorized users, while incorporating innovative teaching affordances. These factors made this environment an ideal venue for a CALL project involving the investigation of learner interaction in virtual worlds.

\subsection{Data collection, coding and analysis}

Data collection occurred in three phases. During the orientation, to obtain background information, the learners completed a pre-study questionnaire. In the next phase, at the start of each task session the researcher, using the data recording feature of Second Life, logged the subjects' text chat. This data was saved to a text file at the end of each session. At this stage, in order to facilitate analysis of the transcripts, automatically generated systems messages were removed. This procedure resulted in the collection of a corpus of 9,902 running words. To establish participation patterns, the researcher analyzed the messages produced in each of the three task sessions. These were first categorized into student-instructor interactions and interactions between students. The frequencies of these interactions were calculated. Student produced messages were then classified into two categories: task-focused and off-task. To provide additional insights on this aspect of the data, the number of turns produced by each participant was calculated. In order to shed light into the subjects' discursive practices and identify significant examples of discourse 
management strategy use, the researcher worked with another coder, an experienced instructor from the same institution, to analyze the messages produced by the subjects. To achieve inter-coder reliability, the two coders working together examined the transcripts collected during the first and second sessions. In analyzing the data, the coders drew on coding categories for strategy use identified in the literature on the use of virtual worlds in CALL (Peterson, 2006).

Analysis of this data revealed the presence of seven discourse management strategies. This process appeared highly effective, with the coders agreeing on $96 \%$ of coding, a finding that indicates a high degree of consistency. Using the categories established previously, the researcher coded the remaining data. These procedures facilitated the calculation of the total number of turns involving strategy use during each session. To obtain additional perspectives and sources of data, observation was conducted and significant events were recorded in field notes. On the completion of the final session, a post-study questionnaire was administered. As a follow-up measure, each participant was interviewed by the researcher and asked to provide feedback on their experiences.

\section{Results}

\subsection{Participation and strategy use in session 1}

The first task administered was open-ended and designed to encourage the subjects to navigate and communicate in Second Life. In the handout, the learners were given directions on how to locate USQ Island and explore specific locations. The handout also contained activities designed to elicit communication between the participants. For example, the subjects were encouraged to contact other learners, respond to questions and give explanations of how features of the environment such as, for example, the avatars operate.

Analysis of the transcripts revealed that the interaction in this session was highly learner-centered. As Table 2 shows, the majority of the messages were exchanged between individual subjects. Only a small minority of messages involved studentresearcher interaction. Observation revealed that these later messages were almost exclusively requests for help in using the communication and navigation features of Second Life. Although an orientation session was conducted, in the early stages of the session some of the subjects experienced difficulties and expressed confusion, as may be observed in the following learner messages:

(1) Researcher: do you all understand how to use the commands?

Student 7: i am not quite sure

(2) Student 4: I can't use gesture function. Why>

However, even at this stage, the majority of the subjects actively participated in the proceedings. A friendly atmosphere soon prevailed, and with one exception the

Table 2 Categories of interactions and frequencies

\begin{tabular}{lrr}
\hline \hline Student-researcher interactions & 18 & $4 \%$ \\
Student-student interactions & 405 & $96 \%$ \\
\hline \hline
\end{tabular}


Table 3 Categories and frequencies of learner messages

\begin{tabular}{lrr}
\hline \hline Task-focused messages & 393 & $93 \%$ \\
Off-task messages & 30 & $7 \%$ \\
\hline \hline
\end{tabular}

Table 4 Categories and frequencies of transactional strategies

\begin{tabular}{lrr}
\hline \hline Transactional strategies & \multicolumn{2}{c}{ Frequencies } \\
\hline \hline Addressivity & 21 & $34 \%$ \\
Split turns & 20 & $32 \%$ \\
Time saving devices & 18 & $29 \%$ \\
Upper case & 3 & $5 \%$ \\
\hline \hline
\end{tabular}

participants overcame initial problems in using the system. The supportive nature of much of the interaction in this session can be observed in the following learner interaction where student 2 offers helpful advice to student 5 on moving their avatar effectively:

(3) Student 5: i can't move

Student 2: then click the go icon

A further encouraging finding was that the interaction in this session was highly task-focused. Researcher observation confirmed that off-task messages were infrequent and largely restricted to the early and later stages of the interaction. As can be seen in Table 3, the majority of messages produced by the subjects were related either directly or indirectly to the task at hand.

This finding was mirrored in the later sessions. Possible explanations for this finding will be examined at a later stage of this discussion. Most postings were rather brief. However, this finding is not in itself surprising, as the subjects were novice users. The total number of turns made by each learner varied from a low of 19 to a high of 77. Student 7 produced the lowest number of turns and this finding may, in part, be due to lateness. Moreover, researcher observation revealed that this subject experienced persistent difficulties in using the communication features of the system. This subject displayed a tendency toward lurking, particularly in the later stages of the session. In contrast, student 6 was the most prolific poster. The researcher's field notes recorded that this subject appeared highly motivated by the context of the interaction.

Analysis of the transcripts further showed that in their messages the subjects used two types of strategy to manage their TL interaction. The first were transactional (Brown \& Yule, 1983) in nature, and were designed to facilitate the efficient exchange of information during the real time computer-based interaction. As Table 4 shows, four types occurred.

The most frequent was the use of addressivity (Werry, 1996). That is, the explicit naming of an intended message recipient at either the beginning or, less frequently, at the end of a message. An example of this strategy may be observed in the following excerpt:

(4) Student 4: You changed your avatar, Adrienanna? 
Mark Peterson

Table 5 Categories and frequencies of interactional strategies

\begin{tabular}{lcr}
\hline \hline Interactional strategies & \multicolumn{2}{c}{ Frequencies } \\
\hline \hline Politeness & 42 & $76 \%$ \\
Keyboard symbols & 13 & $24 \%$ \\
\hline \hline
\end{tabular}

This strategy appeared to provide an efficient means to track turns in the communication context provided by Second Life, where text messages are intermixed and scroll in real time. As can be seen in Table 4, the second most frequent type of transactional strategy involved the splitting of turns. This strategy, known as split turns, has been identified in native speaker text chat (Simpson, 2002). An instance occurred as the subjects experimented with the appearance of their avatars:

(5) Student 6: I create a new gester just by chance

Student 6: lynn your new skirt is good!! beautiful

As the above learner output shows, this strategy provided a useful means to supply additional information and drive the interaction forward. Moreover, the subjects made use of time saving devices such as abbreviation and acronyms:

(6) Student 2: u want to change ur hair?

(7) Student 3: lol

On occasion, the subjects made use of uppercase as a means to display intonation, as in the following message:

(8) Student 2: how can u say HEY with voice, kyoko?

In additional to transactional strategies, interactional strategies were used in an effort to establish and maintain collaborative inter-personal relationships (Brown \& Yule, 1983). As Table 5 shows, two types of interactional strategy were identified and the most frequent was politeness.

Positive forms of politeness were the most frequent and, as the following instances show, these involved the use of humor, colloquialisms and inclusive forms:

(9) Student 6: hi martine!

Student 4: Hi

Student 6: we are like a courple!!

Student 4: Indeed!

(10) Student 2: oh look, cool hair

(11) Student 7: Hey

(12) Student 3: I feel as if we were in the same place in real world

In keeping with the relaxed atmosphere during the session, greetings and leavetakings occurred and these were informal in nature. Greetings were directed to specific individuals or to the group, as may be observed in the following instances:

(13) Student 6: hi martine!

Student 4: Hi 
(14) Student 6: how are u all

Leave-takings were also employed appropriately:

(15) Student 4: Thank you. See you.

Student 7: Bye

(16) Student 4: everyone bye!

As the above examples show, leave-takings were used between individuals or less frequently directed towards the group as a whole. The use of politeness draws attention to the subjects' apparent desire to maintain cooperative relationships with their peers. The further main use of interactional strategies identified in the data, involved adaptive uses of keyboard symbols. These were used to signal various emotional states, as in the following messages:

(17) Student 6: ohhhhhhhhhh. that is too bad

(18) Student 7: oh, sounds nice

A further interesting use of keyboard symbols occurred. As can be seen in excerpt 19, student 3 used strings of dots known as suspension dots that are a feature of native speaker text chat (Cherny, 1999) to signal uncertainty:

(19) Student 3: erm....

On a few occasions, this subject used multiple question marks to display surprise (excerpt 19):

(20) Student 6: what???????? i u in the Iceland

\subsection{Participation and strategy use in session 2}

In the second session, the subjects were requested to exchange opinions on a recent flu outbreak in Japan. Interaction in this session took place at the opinionator venue described in section 3.4. The number of subjects was reduced, as one learner (student 7) was absent due to illness. Transcript data showed a higher number of turns than in session 1 and, as in the previous session, the interaction was highly learner centered. As can be seen in Table 6, the majority of interactions involved message exchange between participants. However, student-researcher interactions were somewhat higher than in the previous session. This was because, on occasion, the researcher contributed to the on-going discussion.

The total number of turns made by each learner varied from a low of 20 to a high of 80 . In contrast to session 1 , the subjects produced more lengthy messages. Student 1 produced the lowest number of turns, followed by student 5 , and this may be the result of these subjects arriving late. In contrast, student 6 remained a consistent poster throughout the session. However, the most prolific participant in this regard

Table 6 Categories of interactions and frequencies

\begin{tabular}{lrr}
\hline \hline Student-researcher interactions & 45 & $10 \%$ \\
Student-student interactions & 398 & $90 \%$ \\
\hline \hline
\end{tabular}


Mark Peterson

Table 7 Categories and frequencies of learner messages

\begin{tabular}{lrr}
\hline \hline Task-focused messages & 165 & $37 \%$ \\
Off-task messages & 278 & $63 \%$ \\
\hline \hline
\end{tabular}

Table 8 Categories and frequencies of transactional strategies

\begin{tabular}{lrr}
\hline \hline Transactional strategies & \multicolumn{2}{c}{ Frequencies } \\
\hline \hline Split turns & 21 & $57 \%$ \\
Addressivity & 8 & $22 \%$ \\
Upper case & 5 & $13 \%$ \\
Time saving devices & 3 & $8 \%$ \\
\hline \hline
\end{tabular}

was student 5. Research observation confirmed that the majority of the subjects made repeated use of the opinionator (see Figure 2) to express their views on questions raised during the on-going discussion.

As may be observed in Table 7, there was a significant increase in off-task messages compared to session 1. Analysis of the transcripts showed that these messages were concentrated at the beginning of the session, and were the result of delays caused by the late arrival of students 1 and 5 . Researcher observation revealed that once these learners joined the discussion, a focus on the task soon became apparent.

The interaction in this session displays the influence of task-induced effects. The task appeared to elicit somewhat longer messages than in session 1, and the subjects engaged in extended discussion, as can be seen in the following interaction:

(21) Researcher: anyone else have an opinion?

Student 4: government does not determine how serious the flu is

Student 2: it confuses me how serious this flu is

Student 4: I think the effect of mass media is strong

Student 2: i am ease to get cold, i am afraid

The data further showed that, on occasion, the subjects appeared reluctant to express opinions:

(22) Researcher: can you all explain your views?

Student 5: actually I do not have enough idea

Student 3: i don't know much about it, to be honest

The transcript data revealed the presence of four transactional strategies in the data. As Table 8 shows, the same strategies identified in session 1 also occurred in this session. However, with the exception of split turns their frequency decreased significantly compared to the previous session. In a further noteworthy difference, the use of split turns emerged as the most frequent transactional strategy. This finding suggests that, as in session 1, the use of this strategy was an effective means to provide additional information. 
Learner participation patterns and strategy use in Second Life

Table 9 Categories and frequencies of interactional strategies

\begin{tabular}{lcc}
\hline \hline Interactional strategies & \multicolumn{2}{c}{ Frequencies } \\
\hline \hline Politeness & 18 & $60 \%$ \\
Keyboard symbols & 12 & $40 \%$ \\
\hline \hline
\end{tabular}

Further similarities and differences between the sessions emerged in the data on interactional strategy use. As can be seen in Table 9, politeness remained the most frequent interactional strategy. As was the case in session 1, the majority of politeness strategies involved the use of positive politeness.

However, compared to session 1, the instance of the strategy was reduced. The transcripts also showed that frequency of keyboard symbols remained similar in total to the previous session. The adaptive strategy of using suspension dots emerged as the primary means to display feedback on emotional states. Moreover, as can be seen in the following excerpts, smileys made their first appearance in the data:

(23) Student 3: i dropped out :(

(24) Student 1: kinpaku^^

As is the case in native speaker text chat (Cherny, 1999), the use of these combinations of keyboard symbols appeared a useful means to signal attention and attitude.

\subsection{Participation and strategy use in session 3}

In session 3, the subjects were requested to locate a specific facility in USQ Island known as the lecture theater (see section 3.4). Each participant was then requested to give a brief mini lecture on a paper that they had been asked to read beforehand. As noted in section 3.3, this task was designed to give the subjects practice in English presentation skills. Analysis of the transcripts indicated that this session involved fewer turns than the others. This finding is most likely due, in part, to one of the subjects - student 1 - arriving too late to give a talk. Moreover, the nature of the task, which required each participant to hold the floor for a prolonged period, may be partly responsible for this finding. As can be seen in Table 10, the student centered nature of the interaction continued, with the majority of the messages involving student-student interaction. The majority of student-researcher interactions involved procedural matters such as selecting the next speaker and, on occasion, eliciting feedback.

The number of turns produced by each learner ranged from 14 to 96 . As was the case in session 2, the subjects produced, on occasion, lengthy messages. Learner 1

Table 10 Categories of interactions and frequencies

\begin{tabular}{lrr}
\hline \hline Student-researcher interactions & 24 & $7 \%$ \\
Student-student interactions & 330 & $93 \%$ \\
\hline \hline
\end{tabular}


Mark Peterson

Table 11 Categories and frequencies of learner messages

\begin{tabular}{lrr}
\hline \hline Task-focused messages & 319 & $(90 \%)$ \\
Off-task messages & 35 & $(10 \%)$ \\
\hline \hline
\end{tabular}

produced the lowest number due to their late arrival in-world. In contrast, learner 6 produced 96 messages and continued to display the high degree of interest shown in the previous sessions.

In an encouraging finding, the high degree of task focus continued. Table 11 shows that the majority of messages were task related. As was the case in session 1, off-task messages were infrequent and largely restricted to the beginning and closing stages of the session.

The transcripts indicated that after initial greetings the subjects quickly focused on the task at hand. As can be seen in the following interaction, they made statements supplying information related to the task, interrupted and responded appropriately:

(25) Student 4: The purpose was to examine the Japanese chat data in order to know specific types of communication difficulties.

Student 4: Japanese native speakers and learner of Japanese were talking in the virtual world.

Student 2: sorry for interrupting, which article do you explain?

Student 4: Sorry, I chose categorization of text chat communication between earners and native speakers of Japanese

Student 2: thank u i see

The participants also made efforts to explore issues raised by the papers they had read, as in the following excerpt from a later stage of the above interaction, which contains a rare example of L1 use:

(26) Student 4: The authors say they can make recommendations on how the quality of communication can be improved,

Student 2: i have a question about the conclusion part

Student 4: Yes, go ahead

Student 4: it is said in the conclusion section,

Student 2: yes

Student 4: there were some language aspects that are cricial for communication but that had been neglected in teaching

Student 2: Yes

Student 4: can you give me an exaple of this kind of linguistic aspect?

Student 2: Mavy as the authors suggets,

Student 2: abbreviated sentence is an example

Student 2: Japanse native speakers often use "toka?"

Student 2: In English "How about -?"

Student 2: This causes communication difficulties

Student 2: But that is not taught in ordinary classroon education

Student 4: oh i see, thank u for ur explanation 
Learner participation patterns and strategy use in Second Life

Table 12 Categories and frequencies of transactional strategies

\begin{tabular}{lrr}
\hline \hline Transactional strategies & \multicolumn{2}{c}{ Frequencies } \\
\hline \hline Split turns & 29 & $48 \%$ \\
Time saving devices & 15 & $25 \%$ \\
Addressivity & 7 & $11 \%$ \\
Upper case & 5 & $8 \%$ \\
Quotation marks & 5 & $8 \%$ \\
\hline \hline
\end{tabular}

Table 13 Categories and frequencies of interactional strategies

\begin{tabular}{lrr}
\hline \hline Interactional strategies & \multicolumn{2}{c}{ Frequencies } \\
\hline \hline Politeness & 23 & $74 \%$ \\
Keyboard symbols & 8 & $26 \%$ \\
\hline \hline
\end{tabular}

Transcript data and researcher observation confirmed that this type of in-depth discussion was characteristic of the session. As in the other sessions, the learners followed the requirements of the task and consistently produced coherent TL discourse. They displayed a high degree of interest and engagement while working together collaboratively. Moreover, they gained valuable practice in managing their TL discourse in an authentic setting.

In terms of strategy use, differences emerged from the previous sessions. As Table 12 shows, the use of split turns increased compared to the other sessions. This finding reflects the effectiveness of this strategy as an efficient means to meet the requirements the task.

Moreover, a new transactional strategy emerged, the use of quotation marks. As can be seen in the following instance, in the absence of verbal cues this strategy enabled the participants to signal emphasis:

(27) Student 6: such as use 'u' for 'you'

The learners also occasionally used quotation marks in clarification requests:

(28) Student 2: Sorry what is "that issue"?

Although this strategy was infrequent its appearance nonetheless reflects the way the subjects' adaptive strategy use evolved as the project progressed.

Table 13 shows that the same interactional strategies that appeared previously also occurred in this session. This finding may reflect the success of these strategies in establishing and maintaining collaborative interpersonal relationships. Data analysis showed that the use of both positive and negative politeness continued. As was the case in the other sessions, positive politeness strategies prevailed. This finding draws attention to the friendly and relaxed nature of the interaction.

Occasional instances of negative politeness occurred involving the use of apologies. As can be seen in excerpt 25 , these were used appropriately. 
Mark Peterson

\subsection{Participant attitudes}

In order to investigate learner attitudes toward studying in Second Life a post-study questionnaire was administered. This included 10 Likert scale questions. The participants were requested to select one response for each statement from the following options: 1 strongly disagree, 2 disagree, 3 no opinion, 4 agree and 5 strongly agree. A total of 6 subjects completed the questionnaire. Additional feedback was obtained through interviews. Analysis of responses to the post-study questionnaire is provided in Table 14.

The first statement focused on the accessibility of the environment; the mean rating of 4.3 showed that most subjects agreed with the statement that Second Life was easy to use. In response to statement two, the subjects averaged 3.1. Half the subject group answered this question positively while the others either disagreed or had no opinion. The subjects expressed general agreement with statement three that using the environment helped them to improve their English skills. This was reflected in a mean score of 4.0. In response to statement four the subjects averaged 1.8. The majority expressed clear disagreement with the statement that the discussion was not useful. Echoing this positive finding, there was strong agreement with statements five and six with responses averaging 4.2 and 4.0. These findings show that for the majority of the subjects, Second Life provided worthwhile opportunities to use their English in a low stress setting and at their own pace. In their responses to statement seven the subjects averaged 4.0. This finding indicates a clear preference for tasks. In response to statement eight the learners averaged 4, indicating that the presence of personal avatars enhanced the sense of telepresence. The largely positive responses to statements nine and ten, where the mean scores were 4.3 and 4.7 respectively, draw attention to learner claims that studying in Second Life was more interesting than regular classes and also enjoyable.

Data collected in the post-study interviews provided further insights into the participants' experiences. In their comments to the researcher, the subjects also drew attention to some issues raised by the use of Second Life in CALL. The majority claimed that, initially, they faced problems in dealing with the environment. The rapid scrolling of messages led, on occasion, to confusion and difficulties in keeping up with the interaction. However, as they gained experience, the participants claimed that they became more comfortable. Only one subject, student 7, observed that they

Table 14 Mean scores of responses to the Likert scale items in the post-study questionnaire

Question

1. I found Second Life (SL) easy to use 4.3

2. I could learn new words and expressions

3. Using SL helped me to improve my English

4. Most of the discussion was not so useful

5. A good point of SL is that I could work at my own pace

6. I could express my opinions more freely in SL than in a regular class

7. Being assigned a task was more useful than a general discussion

8. Having my own avatar made me feel more involved

9. Classes held in SL were more interesting than regular classes 
experienced difficulties throughout the project. The learners identified a number of benefits of the interaction. The use of pseudonyms appeared to reduce inhibition and enhance motivation, while the presence of avatars supported immersion and engagement. Four of the subjects claimed they gained knowledge of new vocabulary and useful practice in using the TL. Three learners identified the presentation task as particularly valuable in this regard. Four learners also claimed that their reading speed and typing skills improved during the project.

\section{Discussion}

In the context of answering research question one (What are the significant participation patterns during learner task-based interaction in Second Life?), analysis of the data revealed a number of relevant findings. The transcripts showed that although there were variations in the number of turns made by each participant in the sessions, the majority of messages were exchanged between the subjects. The highly learner centered nature of the interaction represents a positive finding, that lends support to one of the main benefits hypothesized for network-based learning. Namely, that it facilitates learner centered rather than teacher led interaction, which may facilitate the development of learner autonomy (Schwienhorst, 2002). The data collected in this research suggests that for this particular group of learners the context appeared to elicit a high degree of participation and autonomy. Moreover, the data provide evidence of task-induced effects. The tasks appeared to be successful in eliciting active participation and this was reflected in the transcripts, which showed a high degree of task focus. Researcher observation confirmed this finding. With the exception of session 2 where there was a delay in the proceedings caused by lateness, it was observed that the majority of messages were related to the task at hand. There was little evidence of the off-task interaction that has been identified in other studies involving the use of text (Darhower, 2002). Moreover, the transcripts and research observation confirmed that the learners themselves managed their interaction almost entirely in the TL. In another positive finding, there was little evidence of the frequent L1 use that has been identified in studies of learner interaction involving other types of real time CMC (Fernandez-Garcia \& Martinez-Arbelaiz, 2002).

The data further provided evidence relevant to research question two (What strategies do learners use to manage their interaction?). The transcripts showed that the participants made use of five transactional and two interactional strategies to manage their interaction. The subjects' strategy use consisted of a mixture of transfers from non-computer forms of interaction and adaptive behaviors. Analysis indicated that split turns were the most frequent transactional strategy across the three sessions. Learner post-study feedback suggested that this adaptive strategy was a useful means to provide information and move the discourse forward. The presence of addressivity was a somewhat surprising finding. The researcher had anticipated that the use of personal avatars and pseudonyms would render this type of transfer strategy largely redundant. However, its reduced frequency from session 2 onwards suggests that after early difficulties the learners soon became more comfortable with the environment. The presence of upper case and time saving devices represent further transfer strategies that were, for the most part, used successfully. 
The emergence of quotation marks in the final session, though infrequent, demonstrates how the subjects were able adapt their transactional strategy use in a manner appropriate to the online medium.

The most frequent interactional strategy was the use of politeness. Analysis showed that positive politeness was more frequent than negative politeness and this was reflected in the friendly and informal atmosphere that prevailed during the project. The absence of flaming in the data draws attention to the effectiveness of this strategy. Researcher observation and learner feedback confirmed that the participants consistently utilized politeness, as they were eager to establish and maintain collaborative interpersonal relationships. Possible explanations for the prevalence of this strategy may lie in the computer-based nature of the interaction. As many social and paralinguistic cues that influence interaction in face-to-face contexts were not present, the learners appeared to be conscious of the need to avoid misunderstandings. Another factor that may account for the presence of politeness lies in the influence of sociocultural factors. Three of the subjects were Japanese, a culture where maintaining status with peers is an important influence on communication. The use of politeness may reflect a desire to avoid conflicts and reflects the transfer of L1 communicative practices. A final possible explanation may be that the subjects were aware that they were being observed and that the interaction was being recorded. The presence of the adaptive interactional strategy of using keyboard symbols to signal emotional states represents an interesting finding. A possible explanation for the use of this strategy may be the limitations of the avatars used in Second Life, which are able to display only a limited range of facial expressions and emotional states. The subjects appear to have transferred strategies they have used in other types of CMC, such as e-mail, to a new context.

The data gathered to answer research question three (What are learner attitudes toward studying in Second Life?) confirmed that the participants held broadly positive views. The data shows that the majority appreciated the opportunities provided for TL practice. The learners observed that technical issues hampered interaction in the early stages of the project. However, they noted that when these were overcome, the interaction proceeded without major difficulties. They also commented positively on the low stress atmosphere compared to a regular language class. Several of the subjects claimed that using the environment was enjoyable and motivating. Researcher observation confirmed that from the first session, all of the subjects created their own avatars. This finding highlights the degree of engagement engendered by the presence of personal avatars. Although the learners claimed that the interaction was useful, few could provide specific examples of new vocabulary or expressions. This finding, coupled to the presence of errors, suggests that Second Life may provide a venue for the development of language fluency rather than accuracy.

\section{Conclusions}

The largely positive findings identified in this project suggest that Second Life appears a viable platform for learner-based CALL projects involving small groups. However, this study was subject to a number of limitations. As a result of institutional constraints, the number of sessions was restricted. Furthermore, only three 
tasks were administered. Although these factors represent limitations, the findings of this exploratory study draw attention to a number of areas that may be of particular interest in future research. Additional longitudinal studies involving larger learner groups may shed further light on participation patterns. Moreover, studies conducted in different contexts, involving more diverse learner groups have the potential to produce interesting results in this regard. The connection between task type and strategy use remains another area that would benefit from additional research. The influence of the affordances provided by Second Life appears of interest. For example, the role played by avatars in fostering telepresence and participation in virtual worlds represents an area that requires further investigation. This research has shown that Second Life presents a dynamic, motivating and engaging new context for language learners, offering opportunities to participate in beneficial forms of collaborative TL interaction. Future research offers the prospect of obtaining valuable new insights into how the processes at work in second language development may be fostered in the interactional context provided by the online domain.

\section{References}

Blake, R. (2000) Computer mediated communication: A window on L2 Spanish interlanguage. Language Learning \& Technology, 4(1): 120-136.

Brown, G. and Yule, G. (1983) Discourse analysis. Cambridge: Cambridge University Press.

Chapelle, C. A. (2001) Innovative language learning: Achieving the vision. ReCALL, 13(1): 3-14.

Cherny, L. (1999) Conversation and Community: Chat in a Virtual World. Stanford: Center for the Study of Language and Information.

Chun, D. (1994) Using computer networks to facilitate the acquisition of interactive competence. Computer Assisted Language Learning, 22(1): 17-31.

Conacher, J. E. (2004) Review of conversation and technology. Language Learning \& Technology, 8(1): 20-23.

Darhower, M. (2002) Interactional features of synchronous computer-mediated communication in the intermediate L2 class: A sociocultural case study. CALICO Journal, 19(2): 249-277.

Deutschmann, M., Panichi, L. and Molka-Danielsen, J. (2009) Designing Oral Participation in Second Life - A Comparative Study of Two Language Proficiency Courses. ReCALL, 21(2): 206-226.

Fernandez-Garcia, M. and Martinez-Arbelaiz, A. (2002) Negotiation of meaning in nonnative speaker-nonnative speaker synchronous discussions. CALICO Journal, 19(2): 279-294.

Gass, S. M. (2000) Changing views of language learning. In: Trappes-Lomax, H. (ed.), Change and continuity in applied linguistics: Selected papers from the annual meeting of the British Association of Applied Linguistics, Edinburgh. Edinburgh: BAAL, 51-67.

Hampel, R. (2006) Rethinking task design for the digital age: A framework for language teaching and learning in a synchronous online environment. ReCALL, 18(1): 105-121.

Hudson, J. M. and Bruckman, A. S. (2002) IRC Francais: The creation of an Internet-based SLA community. Computer Assisted Language Learning, 15(2): 109-134.

Kern, R. (1995) Restructuring classroom interaction with network computers: Effects on quantity and characteristics of language production. The Modern Language Journal, 25(5): 441-454.

Kötter, M. (2003) Negotiation of meaning and codeswitching in online tandems. Language Learning \& Technology, 7(2): 145-172.

Lee, L. (2001) Online interaction: Negotiation of meaning and strategies used among learners of Spanish. ReCALL, 13(2): 232-244. 
Lee, L. (2002) Synchronous online exchanges: A study of modification devices on non-native discourse. System, 30(3): 275-288.

Long, M. (1996) The role of linguistic environment in second language acquisition. In: Ritchie, W. and Bhatia, T. (eds.), Handbook of research on second language acquisition. New York: Academic Press, 413-469.

Negretti, R. (1999) Web-based Activities and SLA: A Conversation Analysis Research Approach. Language Learning \& Technology, 3(1): 75-87.

Ornberg, T. (2003) Linguistic presence on the Internet: Communication, worldview and presence in online virtual environments. Unpublished master's thesis, University of Umea.

Peterson, M. (2006) Learner interaction management in an avatar and chat-based virtual world. Computer Assisted Language Learning, 19(1): 79-103.

Pica, T., Kanagy, R. and Falodun, J. (1993) Choosing and using communication tasks for second language instruction. In: Crookes, G. and Gass, S. (eds.), Tasks and Language Learning: Integrating theory and Practice. Clevedon: Multilingual Matters, 9-34.

Schroeder, R. (2002) Social interaction in virtual environments: Key issues, common themes, and a framework for research. In: Schroeder, R. (ed.), The Social Life of Avatars: presence and interaction in Shared Virtual Environments. London: Springer-Verlag, 1-18.

Schwienhorst, K. (2002) The state of VR: A meta-analysis of virtual reality tools in second language acquisition. Computer-Assisted Language Learning, 15(3): 221-239.

Simpson, J. (2002) Discourse and synchronous computer-mediated communication: Uniting speaking and writing. In: Thompson, P. and Spelman Miller, K. (eds.), Unity and diversity in language use. London: Continuum, 57-71.

Smith, B. (2003) Computer-mediated negotiated interaction: An expanded model. The Modern Language Journal, 87(1): 38-57.

Svensson, P. (2003) Virtual worlds as arenas for language learning. In: Felix, U. (ed.), Language learning online: towards best practice. Lisse: Swets \& Zeitlinger, 123-142.

Swaffar, J. (1998) Networked language learning: Introduction. In: Swaffar, J., Romano, S., Arens, K. and Markley, P. (eds.), Language learning online: Theory and practice in the ESL and L2 computer classroom. Austin: Labyrinth Publications, 1-15.

Toyoda, E. and Harrison, R. (2002) Categorization of text chat communication between learners and native speakers of Japanese. Language Learning and Technology, 6(1): 82-99.

Tudini, V. (2003) Using native speakers in chat. Language Learning \& Technology, 7(3): 141-159.

Von Der Emde, S., Schneider, J. and Kötter, M. (2001) Technically speaking: Transforming language learning through virtual learning environments (MOOs). The Modern language Journal, 85(2): 211-225.

Waggoner, M. (1992) A case study approach to the evaluation of computer conferencing. In: Kaye, A. R. (ed.), Collaborative learning through computer conferencing: The Najaden Papers. Berlin: Springer-Verlag, 137-146.

Warner, C. N. (2004) It's just a game right? Types of play in foreign language CMC. Language Learning \& Technology, 8(2): 69-87.

Warschauer, M. and Kern, R. (2000) Introduction: Theory and practice of network-based language teaching. In: Warschauer, M. and Kern, R. (eds.), Network-based language teaching: Concepts and practice. New York: Cambridge University Press, 1-19.

Werry, C. C. (1996) Linguistic and interactional features of Internet Relay Chat. In: Herring, S. C. (ed.), Computer-mediated communication: Linguistic, social and cross-cultural perspectives. Amsterdam: John Benjamins, 47-63. 